\title{
Nontraumatic Hemobilia in Children
}

\author{
Anjana Bairagi ${ }^{1}$ Daniel C. Aronson ${ }^{1}$ \\ ${ }^{1}$ Department of Paediatric Surgery, Inkosi Albert Luthuli Central \\ Hospital, University of Kwazulu-Natal, Durban, South Africa \\ Eur J Pediatr Surg Rep 2015;3:23-26.
}

\begin{abstract}
Address for correspondence Daniel C. Aronson, Department of Paediatric Surgery, Inkosi Albert Luthuli Central Hospital, University of Kwazulu-Natal, Private Bag X03, Mayville 4058, Durban, South Africa (e-mail: aronson.dc@hotmail.com).
\end{abstract}

\begin{abstract}
Keywords

- nontraumatic

- hemobilia

- children

Nontraumatic hemobilia is a rare cause of upper gastrointestinal hemorrhage in children. In the developing world, infections and inflammation are the two most common causes. Two patients are presented illustrating the diagnostic difficulties. Following recognition of the site of bleeding the surgery was successful in each case. After a review of the literature, a diagnostic workup is proposed.
\end{abstract}

\section{Introduction}

Hemobilia is a rare cause of upper gastrointestinal bleeding in children and usually follows trauma to the hepatobiliarypancreatic system. Hemobilia was first described in the 17th century by Francis Glisson. He described his findings of a fatal hemorrhage from the biliary tree secondary to a traumatic liver laceration. In 1948, Sandblom was the first to define hemobilia as hemorrhage arising from trauma in the biliary tract. There is a paucity of data regarding nontraumatic hemobilia, especially in children. The most common etiologies reported in adults are infections, infestations, or neoplasms. The classic triad of upper abdominal pain, melena, and jaundice (Quinke, 1871) was reported in just $22 \%$ of adult patients. ${ }^{1}$ The advent of endoscopy and interventional radiology raises the possibility of noninvasive management. Due to its rarity, this condition continues to be a diagnostic challenge in pediatric surgical patients. We present two patients with nontraumatic hemobilia, a review of the current literature, and propose a diagnostic algorithm.

\section{Case 1}

A 4-year-old female was referred with a weeks' history of hematemesis and passing melena stools. She was transfused a unit of packed cells at base hospital before referral. The patient had a history of similar vomiting a year ago and also complained of intermittent abdominal pain since the age of 1 year. There was no history of trauma. On clinical examination, the patient was found to be hemodynamically stable with some pallor and no other contributory findings. The

received

December 16, 2013

accepted after revision

February 5, 2014

published online

July 30, 2014 patient had a normocytic, normochromic anemia of hemoglobin $(\mathrm{Hb}) 7.1 \mathrm{~g} / \mathrm{dL}$ (normal 10.7-13.1 g/dL) and hematocrit of $21.8 \%$. The remaining laboratory investigations were unremarkable. An upper gastrointestinal endoscopy revealed a normal esophagus, stomach, and D1 (duodenum). At D2 (duodenum), blood was noted at the ampulla of Vater and at the floor of the duodenum ( - Fig. 1). At abdominal ultrasound, a $4.8 \times 4.2 \mathrm{~cm}$ heterogeneous mass in the midline with avid color uptake (suggestive of a vascular mass) and mixed flow was found. Computed tomography angiography (CTA) findings were suggestive of a large pseudoaneurysm arising from the splenic artery with and associated thrombus ( - Fig. 2). The patient was then taken to theater and an exploratory laparotomy was performed. Intraoperative findings were that of a large pancreatic cyst, closely adhered to the posterior wall of the stomach, and involving most of the pancreas except for the tail and a rim of the pancreatic head. The posterior wall of the cyst was closely adhering to the superior mesenteric vein and portal vein. Thus the cyst was deroofed ( - Fig. 3) and an extended distal pancreatectomy performed. The splenic artery was ligated and spleen was found to be grossly normal. Postoperative management included prophylactic antibiotics, somatostatin infusion, and total parenteral nutrition. A week later, the patient was tolerating full diet and was discharged home. At her 4 month outpatient clinic review, the patient was doing well with no signs of exocrine or endocrine pancreatic insufficiency. The final histology results were: pancreatic tissue with inflammation, hemosiderin, fibrosis, and granulation. These features are in keeping with a pancreatic pseudocyst.
License terms

Stuttgart · New York

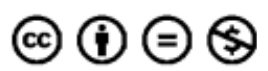

DOI http://dx.doi.org/

10.1055/s-0034-1372462. ISSN 2194-7619. 


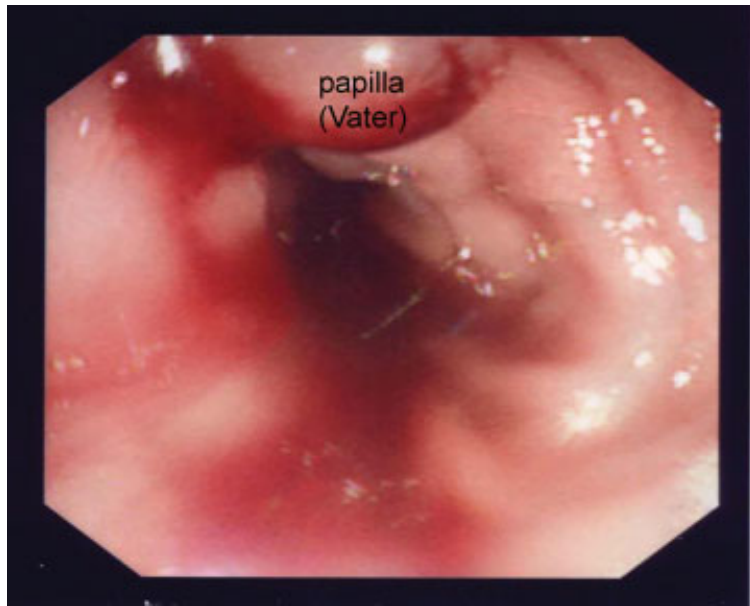

Fig. 1 Hemobilia at endoscopy. Note the blood at ampulla of Vater.

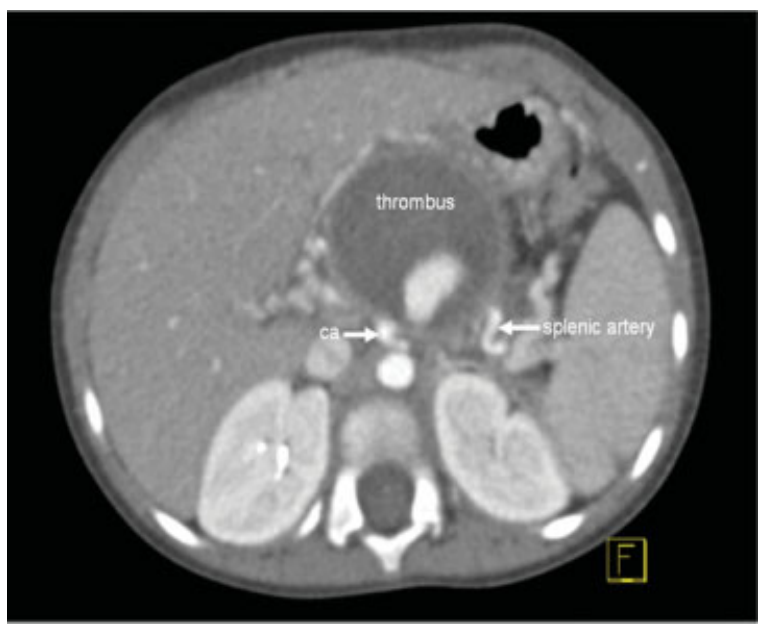

Fig. 2 CTA showing a large pseudoaneurysm arising from the splenic artery with an associated thrombus. ca, celiac axis; CTA, computed tomography angiography.

\section{Case 2}

An 11-year-old female was referred with 1 month history of jaundice, hematemesis, and melena $(\sim 1 \mathrm{~L})$ over 2 days. The patient had no travel history, and a negative malaria screen. A diagnostic ultrasound done at base hospital showed an abnormal liver echo structure with dilated intrahepatic ducts and portal vein. The CT scan showed an enlarged gallbladder, and an irregular biliary tree dilatation. Upper endoscopy findings were that of bleeding from the ampulla of Vater. The patient had anemia of $\mathrm{Hb} 4.2 \mathrm{~g} / \mathrm{dL}$ (normal 11.5-14.5 g/dL) and international normalized ratio 1.33. Before transfer for further management, the patient was transfused two units of blood, given freeze dried plasma, vitamin $\mathrm{K}$, and commenced on antibiotics. The patient arrived hemodynamically stable with a blood pressure 122/72 mm Hg, pulse rate 102/min. A soft, nontender mass was palpable in the right upper quadrant. There was no melena on digital rectal examination. The patient

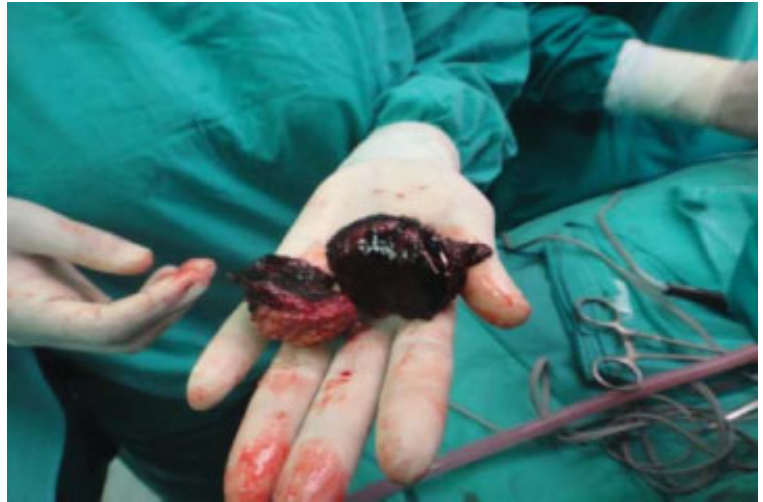

Fig. 3 The deroofed cyst containing thrombus.

arrived with $\mathrm{Hb} 9.7 \mathrm{~g} / \mathrm{dL}$ and deranged liver function tests. Diagnostic CTA demonstrated multiple saccular aneurysms of the right hepatic artery, dilated intrahepatic ducts up to the common hepatic duct, a $3.1 \times 1.8 \mathrm{~cm}$ hyper dense mass in the porta hepatis with mass effect on the proximal common bile duct (CBD) and cystic duct and lastly, a grossly dilated gallbladder containing sludge. We proceeded to perform an exploration of this porta hepatis mass. A much enlarged gallbladder was encountered which was removed via a retrograde cholecystectomy. The CBD was obstructed, dilated, and draped over a mass thought to be a right hepatic artery aneurysm. The right hepatic artery was ligated, the mass deroofed and its posterior wall left in situ as it was densely adherent to the portal vein. The CBD was excised and the distal CBD ligated flush with the superior part of the duodenum. A standard hepaticojejunostomy and enteroenterostomy was performed to restore bowel continuity. The patient had an uneventful postoperative recovery and on day 6 was discharged to base hospital. Final histology results confirmed a choledochal cyst with associated inflammatory changes and a blood clot-filled gallbladder with mild wall edema.

\section{Discussion}

Hemobilia arises when there is a fistula between the splanchnic circulation and the biliary tree. Bleeding may originate from the hepatic circulation, the vessels of the hepatoduodenal ligament, the extra hepatic biliary tree, the gallbladder, and the pancreas.

Nontraumatic hemobilia is rare in children and many patients do not present with the classic triad of biliary colic, obstructive jaundice, and intestinal bleeding. ${ }^{2}$

The most commonly reported causes of nontraumatic hemobilia in children are infection (liver abscess, ${ }^{3,4}$ parasitic infestation [ascariasis], ,5 anatomical abnormalities [gastric duplication ${ }^{7}$ ], biliary pathology [papillomatosis of the gallbladder, $^{8}$ gallbladder polyps ${ }^{9}$ ) and bleeding disorders (von Willebrand disease). ${ }^{10}$ Other documented nontraumatic causes that have been described in adults include tumors (malignant $^{11,12}$ or benign ${ }^{13}$ ), systemic lupus erythematosus, ${ }^{14}$ sarcoidosis, ${ }^{15}$ biliary pathology (cholelithiasis, 
Table 1 Differences of the etiology of hemobilia in children and adults as described in the literature

\begin{tabular}{|l|}
\hline Etiology \\
\hline Children \\
\hline Ascaris lumbricoides infestation \\
\hline Liver abscess \\
\hline Pancreatitis \\
\hline Gastric duplication \\
\hline Choledochal cyst \\
\hline Gall bladder papillomatosis \\
\hline Gall bladder polyps \\
\hline von Willebrand disease \\
\hline Adults \\
\hline Tumors (malignant/benign) \\
\hline Systemic lupus erythematosus \\
\hline Sarcoidosis \\
\hline Cholecystitis \\
\hline Cholelithiasis \\
\hline Gall bladder ulcer \\
\hline Pancreatitis \\
\hline Warfarin therapy \\
\hline
\end{tabular}

cholecystitis, choledochal cyst, ${ }^{16}$ gallbladder ulcer $^{17}$ ), pancreatitis, and warfarin therapy ( - Table 1 ).

Patients may present with symptoms of an upper gastrointestinal bleed in a chronic or an acute manner. The history of melena may be profuse or minimal, intermittent or continuous. Rapid hemobilia may present as acute lifethreatening hemorrhage even in the subset of nontraumatic hemobilia. Parasitic infestations, endemic to our environment, followed by inflammation are the more common etiology. ${ }^{18}$ One should obtain a comprehensive history including patient's previous admission, and recent travel. Hemosuccus pancreaticus (HP), sometimes called "wirsungorrhagia," is defined as upper gastrointestinal hemorrhage from the papilla of Vater via the pancreatic duct. ${ }^{19} \mathrm{HP}$ most commonly occurs in males aged 50 to 60 years and is associated with pseudoaneurysm formation secondary to chronic pancreatitis. ${ }^{19}$ This pseudoaneurysm communicates with the pancreatic duct through a pancreatic pseudocyst or a fistula secondary to the destruction of its walls by enzymatic injury and compression. Subsequent rupture of the pseudoaneurysm results in HP. This diagnosis is uncommon, if not rare in the pediatric population. ${ }^{20}$ Pseudoaneurysm formation is a known complication of chronic pancreatitis (pancreatic cyst) as described in the first patient. ${ }^{20}$ This can also be a complication of a choledochal cyst as per second described patient. While both hemobilia and HP may overlap in terms of definition and findings on diagnostic endoscopy one should bear them in mind when faced with such patients.
Hydatid infections of the liver caused by Echinoccocus granulosum, result in inflammation of perivascular tissue and weakening of vessel walls. The subsequent pseudoaneurysm formation may rupture into the biliary tree and result in hemobilia. ${ }^{21}$ The most common nematode and trematodes to infect the liver are Ascariasis lumbricoides, Clonoris sinensis, and Fasciola hepaticum. Biliary ascariasis with associated intrahepatic pseudoaneurysm following antihelminthic treatment has been described by our institution. ${ }^{18}$ Although, exceedingly rare, the development of an ascariasis-related pseudoaneurysm was presumed after inflammatory involvement of the artery by a contiguous liver abscess that may rupture into the biliary tree. ${ }^{18,21}$

When hemobilia is suspected one should exclude coagulopathy and should complete a parasitic screen. Sonographic demonstration of the "four-line sign" (nonshadowing echogenic strips with central anechoic tube representing the parasites' digestive tract) is pathognomonic of biliary ascariasis. ${ }^{18}$ Ultrasound may also be helpful in identifying other causes of hemobilia, for example, liver abscess. When the patient is hemodynamically stable upper endoscopy is necessary to identify blood at the ampulla of Vater confirming a diagnosis of hemobilia and excluding more common causes of upper gastrointestinal bleeding. Where available, CTA may identify the source of the hemorrhage and assist in planning the management of these patients.

-Fig. 4 shows a proposed diagnostic algorithm. The advent of interventional radiology has contributed successfully to the nonsurgical management of many of these patients but in small children the size of the vasculature may limit the options for cannulation and subsequent instrumentation.

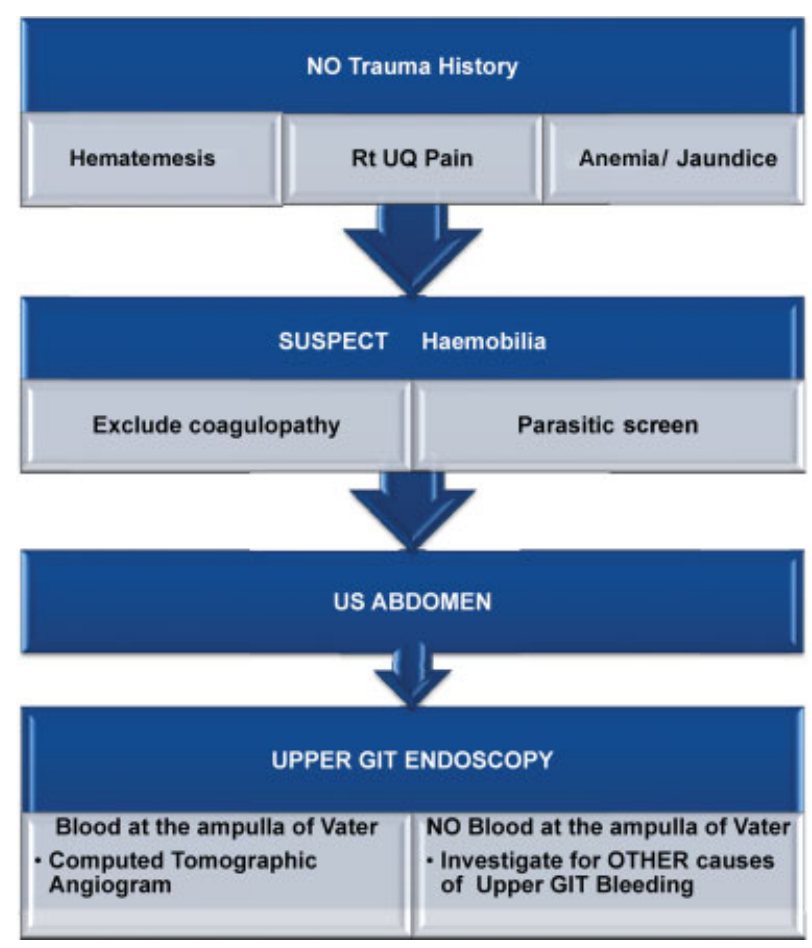

Fig. 4 Diagnostic approach for suspected non traumatic hemobilia. 


\section{Conclusion}

Nontraumatic hemobilia is a rare cause of upper gastrointestinal hemorrhage in children. A systematic approach as proposed above, should ensure timely diagnosis, and guide appropriate management of these patients.

Conflict of Interest

None.

\section{References}

1 Green MHA, Duell RM, Johnson CD, Jamieson NV. Haemobilia. Br J Surg 2001;88(6):773-786

2 Wani NA, Gojwari TA, Khan NA, Kosar TL. Hemobilia in a child due to right hepatic artery pseudoaneurysm: multidetector-row computed tomography demonstration. Saudi J Gastroenterol 2011; 17(2):152-154

3 Khalil A, Chadha V, Mandapati R, et al. Hemobilia in a child with liver abscess. J Pediatr Gastroenterol Nutr 1991;12(1):136-138

4 Awasthy N, Juneja M, Talukdar B, Puri AS. Hemobilia complicating a liver abcess. J Trop Pediatr 2007;53(4):278-279

5 Lloyd DA. Hepatobiliary ascariasis in children. Surg Annu 1982; 14:277-297

6 Baiocchi N, Eyzaguirre M, Hernández H, et al. Hemobilia caused by Ascaris lumbricoides [in Spanish]. Bol Med Hosp Infant Mex 1984; 41(5):291-293

7 Kaneko K, Ando H, Watanabe Y, Seo T, Harada T, Ito F. Gastric duplication communicating with the left hepatic duct: a rare case of recurrent hemobilia in a child. J Pediatr Surg 1999;34(10): 1539-1540

8 Garavelli L, Rosato S, Mele A, et al. Massive hemobilia and papillomatosis of the gallbladder in metachromatic leukodystrophy: a life-threatening condition. Neuropediatrics 2009;40(6): 284-286
9 Ergashev NSh, Khamraev AD, Ochilov NO, Khalikov KhA, Boltaev GS. Hemorrhage from polyp of the gallbladder in a child [in Russian]. Vestn Khir Im I I Grek 1989;143(7):77-78

10 Kaafarani H, Taher A, Haddad MC, Haidar A, Mourad FH. Spontaneous intracholecystic bleeding in a patient with von Willebrand's disease. Gastrointest Endosc 2003;58(5):809-811

11 Hernández-Castillo E, Garduño-López AL, Mondragón-Sánchez R, Bernal-Maldonado R, Mondragón-Sánchez A. Haemobilia and gallbladder carcinoma. Dig Liver Dis 2002;34(9):681-682

12 Lee KE, Kim CW, Kim MJ, et al. Massive bleeding hemobilia occurred in patient with hepatocellular carcinoma [in Korean]. Korean J Gastroenterol 2013;61(1):46-49

13 Sen I, Raju RS, Vyas FL, Eapen A, Sitaram V. Benign biliary papillomatosis in a patient with a choledochal cyst presenting as haemobilia: a case report. Ann R Coll Surg Engl 2012;94(1):e20-e21

14 García Pérez R, Ruiz de Angulo D, López Poveda MJ, Febrero Sánchez B, Navas Carrillo D, Parrilla Paricio P. Hemorrhagic cholecystitis and hemobilia: two infrequent complications of systemic lupus erythematosus. Rev Esp Enferm Dig 2011;103(8):431-433

15 Pollack BJ, Chak A, Dahman B, Sivak MV Jr. Warfarin therapy complicated by recurrent hemobilia in a patient with sarcoidosis. Gastrointest Endosc 1997;46(1):72-76

16 Koh PS, Yoong BK, Vijayananthan A, Nawawi O, Mahadeva S. Jaundice and life-threatening hemobilia: an uncommon presentation of choledochal cyst. J Dig Dis 2013;14(8):451-454

17 Contini S, Uccelli M, Sassatelli R, Pinna F, Corradi D. Gallbladder ulcer eroding the cystic artery: a rare cause of hemobilia. Am J Surg 2009;198(2):e17-e19

18 Corr P, Smit J, Hadley GL. An unusual cause of haemobilia: biliary ascariasis. Pediatr Radiol 1997;27(4):348-349

19 Han B, Song Z-F, Sun B. Hemosuccus pancreaticus: a rare cause of gastrointestinal bleeding. Hepatobiliary Pancreat Dis Int 2012; 11(5):479-488

20 Janarthanan K, Balalakshmoji D, Sanathkumar HT, Suthakaran PK. Chronic pancreatitis presenting with pseudocyst of pancreas and pseudo-aneurysm of hepatic artery. Indian J Pediatr 2012;79(7): 952-954

21 Chin MW, Enns R. Hemobilia. Curr Gastroenterol Rep 2010;12(2): 121-129 